\title{
EFFECTS OF LOW INTENSITY SHOT PEENING TREATMENTS APPLIED WITH DIFFERENT TYPES OF SHOTS ON THE FATIGUE PERFORMANCE OF A HIGH- STRENGTH STEEL
}

\author{
E. Segurado $^{1 *}$, F.J. Belzunce ${ }^{1}$ and I. Fernández Pariente $^{1}$ \\ ${ }^{1}$ Escuela Politécnica de Ingeniería de Gijón (University of Oviedo), Campus universitario, 33203 \\ Gijón, Spain*Contact: seguradomaria@uniovi.es
}

\begin{abstract}
The aim of this research is to study the fatigue life enhancement produced in a quenched and tempered AISI4340 steel with a tensile strength of $2000 \mathrm{MPa}$ after being submitted to shot peening surface treatments. These treatments generate compressive residual stress fields in a superficial layer of the material at the same time as inducing some kind of damage on the surface. Different kind of projectiles were chosen to perform the treatment (ceramic and steel shots), studying the way these affected the fatigue life of the specimens.

The surface topography of the samples was analysed using a roughness tester and by means of scanning electron microscopy (SEM). The compressive residual stress profile induced by these treatments was measured using X-ray diffraction (XRD) plus electro-polishing. The fatigue behaviour of the treated samples was subsequently studied by means of 4-point rotating bending tests and their fracture surfaces were analysed using SEM.

The best fatigue performance was obtained after shot peening with ceramic beads under an $8 \mathrm{~A}$ Almen intensity. The main difference in relation to the treatment performed under the same intensity but using steel cut wire shots was the much lower surface damage induced by the impacts with the ceramic shots compared with the cut wire projectiles, which in turn is justified by the greater geometric perfection and hardness of the former. Furthermore, fatigue specimens shot peened with ceramic beads under an $8 \mathrm{~A}$ intensity always gave rise to internal fatigue crack initiation, which took place outside the zone subjected to residual compressive stresses. Moreover, fatigue initiation was always linked to the presence of hard and rigid alumina inclusions, which acted as microstructural stress concentrators.
\end{abstract}

KEYWORDS: Fatigue, shot peening, surface treatments, residual stress, structural steels. 


\section{INTRODUCTION}

Shot peening is a widely used surface treatment in the aerospace and automotive industries to improve the fatigue life of metal components. When these components are submitted to bending or torsion loads and also when there are stress concentrators, the largest stress occurs on the surface and it is precisely here where fatigue cracks initiate under cyclic loads and then grow until failure of the component.

Shot peening is a mechanical surface treatment specially designed to improve the fatigue behaviour of engineering components. Shot peening consists in blasting tiny spherical beads or balls at high speed onto the metal surface of the component to induce a surface plastic deformation that produces a compressive residual stress profile with a sufficient depth to delay or even avoid the growth of surface cracks under fatigue loads. Shot peening also modifies the surface finish. Furthermore, if the intensity of the treatment is excessive, it can produce superficial defects that may facilitate the easy initiation of surface cracks and thereby impair the fatigue life of the product $[1,2,3]$.

There are many parameters involved in shot peening which need to be controlled in order to produce the expected increase in fatigue performance. There are parameters depending on the shot, as shot shape, size, density and hardness, others depend on the shot peened component or target, as geometry, yield strength, hardness and work-hardening characteristics and, finally, there are other parameters depending on the process, as mass flow rate, air pressure, impact angle and velocity, stand-off distance and coverage.

Numerical models are very efficient tools for simulating shot impacts on specific targets for establishing quantitative relationships between shot and target parameters and residual stress profiles. Nevertheless, the complexity of numerical modelling is evident, as shot peening is a dynamic problem in which a huge number of tiny impacts are involved and a great computational cost is required. A stream of so many shots impacting on a target, along with shot-shot collisions and interactions between incoming shots and rebounding shots is difficult to be modelled by means of finite element methods. Another important aspect to perform a reliable simulation of the shot peening process is the selection of the constitutive model that better describes the behaviour of the target material, which must take into account strain rate effects and cyclic stresses. Many recent contributions were published in this topic [4,5,6,7].

The optimal peening intensity to obtain the best fatigue performance, which depends on the hardness or the mechanical strength of the treated steel, has been experimentally studied by numerous researchers $[8,9,10,11]$. Menéndez et al. [12,13] studied the effects of shot peening onto an AISI4340 steel obtained after quenching and tempering at the same temperatures used in this work, reporting an optimal Almen intensity ranges of 14A. These authors also showed that, under optimal shot peening treatments, fatigue cracks could initiate below the surface at a depth where the compressive residual stresses induced in the shot peening treatment disappeared. Hence, under these optimized treatments, the compressive layer should be able to fully protect the surface region and crack initiation would be displaced to deeper sites, related to the presence of microstructural heterogeneities or stress concentrators, such as hard and rigid non-metallic inclusions.

For the mechanical surface treatment of high strength steels, such as AISI 4340 quenched and tempered at low temperatures, single peening using fine ceramic shots under low Almen intensities are recognized and used industrially to obtain significant high fatigue life improvements under quite low operating peening costs. Peng et al [14] studied the effects of using alumina ceramic beads with a diameter of $0.3 \mathrm{~mm}$ and a hardness of $700 \mathrm{HV}$ under an Almen intensity of 6A compared to using 
cast steel balls with a diameter of $0.6 \mathrm{~mm}$ and a hardness of $610 \mathrm{HV}$ under an Almen intensity of 20A. Higher compressive stresses and hardness in the first $25 \mu \mathrm{m}$ were measured in the samples peened with ceramic beads, though a lower compressive residual stress depth. In this respect, zirconia is a very interesting ceramic medium, characterized by quite a high specific gravity $\left(4.6 \mathrm{~g} / \mathrm{cm}^{3}\right)$, high hardness $(1000 \mathrm{HV})$ and excellent toughness. The possibility of obtaining residual stress profiles as deep as those obtained with steel shots using lower Almen intensities has also been reported, while shot consumption can be reduced for the same Almen intensity as zirconia beads are much stronger than other ceramic shots [15].

In this paper, the effectiveness of fine zirconia ceramic beads for shot peening high strength steels was verified and compared with the use of steel shots with the ultimate goal of increasing the fatigue performance of the steel. In this respect, it should be noted that there are scarcely any scientific references in the literature comparing the effect of using zirconia ceramic beads with steel shots on this particular application.

\section{EXPERIMENTAL PROCEDURE}

\subsection{Materials}

The study was performed on a 41NiCrMo7-3-2 steel (AISI 4340) supplied in bars with a nominal diameter of $16 \mathrm{~mm}$. Table 1 shows the chemical composition of the steel.

Table 1. Chemical composition of AISI 4340 steel, in weight $\%$.

\begin{tabular}{|l|l|l|l|l|l|l|}
\hline $\mathrm{C}$ & $\mathrm{Mn}$ & $\mathrm{Si}$ & $\mathrm{Ni}$ & $\mathrm{Cr}$ & $\mathrm{Mo}$ & $\mathrm{Cu}$ \\
\hline 0,41 & 0,71 & 0,26 & 1,92 & 0,87 & 0,23 & 0,21 \\
\hline
\end{tabular}

The bars were austenitized at $850^{\circ} \mathrm{C}$ for 45 minutes, quenched in water and tempered at $200^{\circ} \mathrm{C}$ for 2.5 hours. The heat treated steel had a final hardness of $552 \mathrm{HV}$. The aforementioned heat treatment was carried out on several steel bars measuring $300 \mathrm{~mm}$ in length. Subsequently, two different types of specimens were machined: (a) flat slices with a thickness of $10 \mathrm{~mm}$, obtained cross-sectioning the bar, and (b) fatigue specimens.

Table 2 shows the values of the elastic modulus $(E)$, yield strength $\left(\sigma_{y}\right)$, ultimate tensile strength $\left(\sigma_{u}\right)$, tensile elongation (e), reduction of area (RA) and the constants $\mathrm{k}$ and $\mathrm{n}$ of the Hollomon hardening law $\left(\sigma=K \varepsilon^{\mathrm{n}}\right)$, obtained in previous studies $[12,13]$.

Table 2. Tensile properties of AISI 4340 steel $\left(\mathrm{Q}+\mathrm{T} 200^{\circ} \mathrm{C}\right)$

\begin{tabular}{|l|l|l|l|l|l|l|}
\hline $\begin{array}{l}\mathrm{E} \\
(\mathrm{GPa})\end{array}$ & $\begin{array}{l}\sigma_{\mathrm{y}} \\
(\mathrm{MPa})\end{array}$ & $\begin{array}{l}\sigma_{\mathrm{u}} \\
(\mathrm{MPa})\end{array}$ & $\begin{array}{l}\mathrm{e} \\
(\%)\end{array}$ & $\begin{array}{l}\text { RA } \\
(\%)\end{array}$ & $\mathrm{n}$ & $\begin{array}{l}\mathrm{k} \\
(\mathrm{MPa})\end{array}$ \\
\hline 200 & 1596 & 2000 & 11 & 50 & 0.24 & 5029 \\
\hline
\end{tabular}

\subsection{Shot peening treatments.}

Shot peening treatments were performed using a direct compressed air machine (Guyson Euroblast 4 PF) with a $5 \mathrm{~mm}$ diameter nozzle, a distance between the nozzle and the workpiece of $230 \mathrm{~mm}$ and an impact angle of $90^{\circ}$, in accordance with the SAE J442 [16] and J443 [17] specifications. 
These treatments were performed using two different types of shots: cut steel wire with rounded off edges (CW) with diameters of $0.3 \mathrm{~mm}, 0.5$ and 0.7 and zirconia beads, Zirshot Y300 (ZS), with a diameter of $0.3 \mathrm{~mm}$. Table 3 shows the most relevant shots characteristics and peening conditions. An Almen intensity of $8 \mathrm{~A}$ was used in the comparison of both shots, though higher intensities were also applied with the steel shots. Coverages of $100 \%$ were applied and an additional coverage of $200 \%$ was also employed when using the ceramic shots.

Table 3: Shot characteristics and peening conditions

\begin{tabular}{|c|c|c|c|c|}
\hline & CW0.3 & CW0.5 & CW0.7 & ZS0.3 \\
\hline Shot type & Steel & Steel & Steel & Zirconia \\
\hline Granulometry (mm) & 0.3 & 0.5 & 0.7 & 0.3 \\
\hline Hardness (HV) & $670-730$ & $670-730$ & $670-730$ & 1000 \\
\hline Density (g/cm $\left.\mathbf{c m}^{\mathbf{3}}\right)$ & 7.8 & 7.8 & 7.8 & 4.6 \\
\hline Air pressure (bar) & 2 & 3 & 3 & 2 \\
\hline Almen intensity & $8 \mathrm{~A}$ & $14 \mathrm{~A}$ & $19 \mathrm{~A}$ & $8 \mathrm{~A}$ \\
\hline Coverage & $100 \%$ & $100 \%$ & $100 \%$ & 100 and $200 \%$ \\
\hline
\end{tabular}

Figure 1 shows SEM images of all the shots, steel cut wire (different sizes) and zirconia beads, while Figure 2 compares the $0.3 \mathrm{~mm}$ steel and ceramic projectiles at a higher magnification. The plastically deformed surface of the steel shots and the perfect spherical shape of the zirconia beads are worth noting.

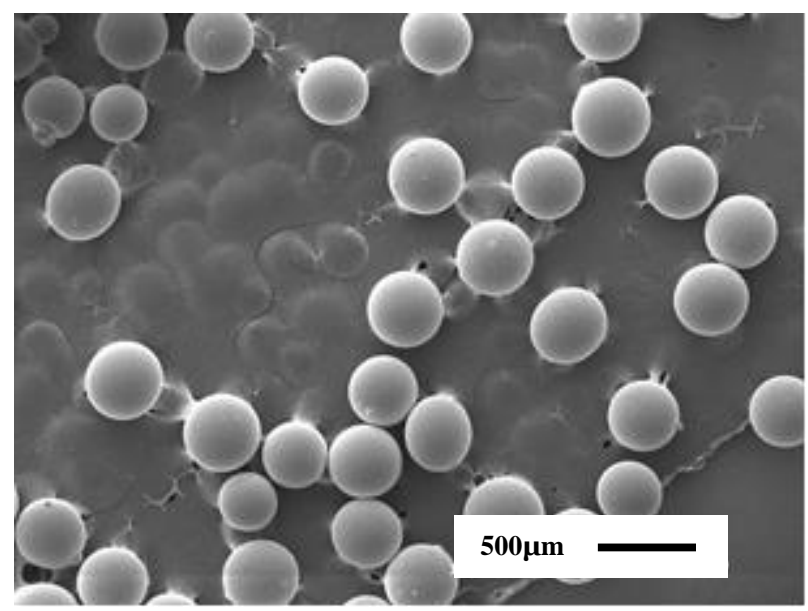

a)

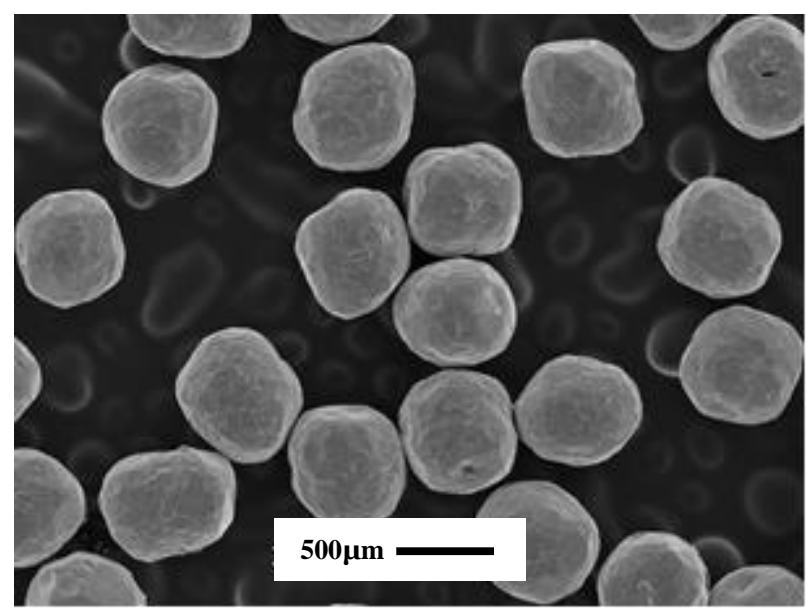

c)

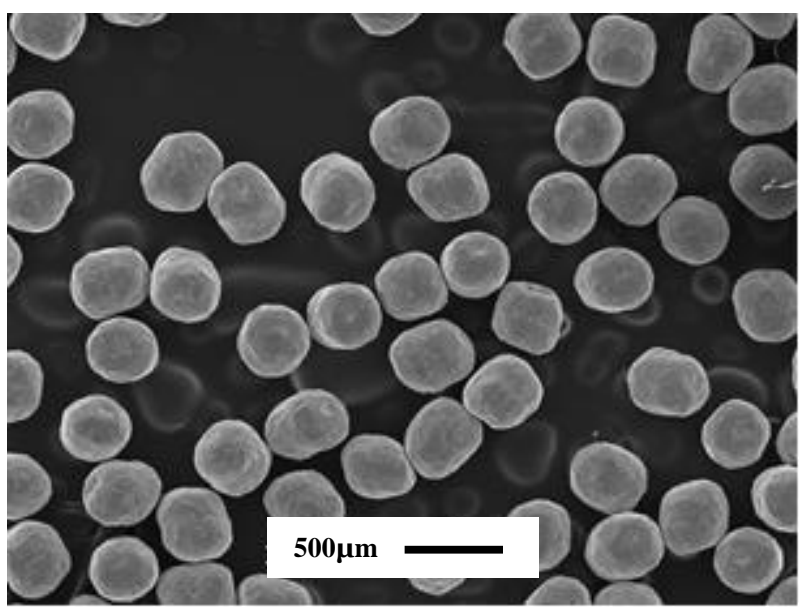

b)

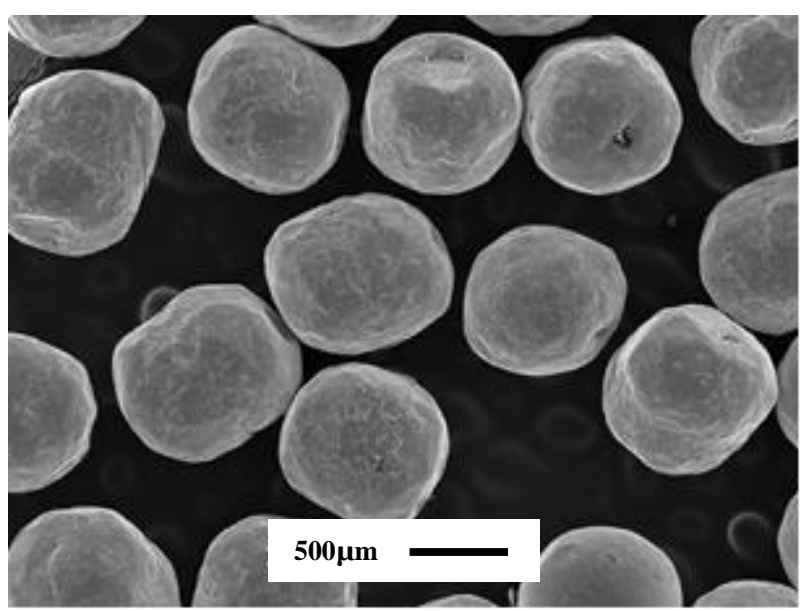

d) 
Figure 1. Shot morphologies at 30x, a) ceramic, ZSO.3, b) steel, CW0.3, c) steel, CW0.5, d) steel, CW0.7

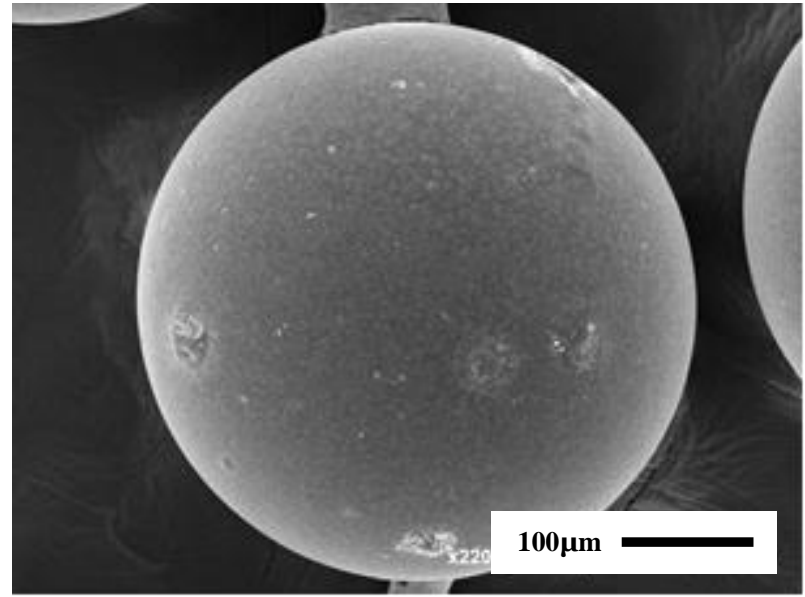

a)

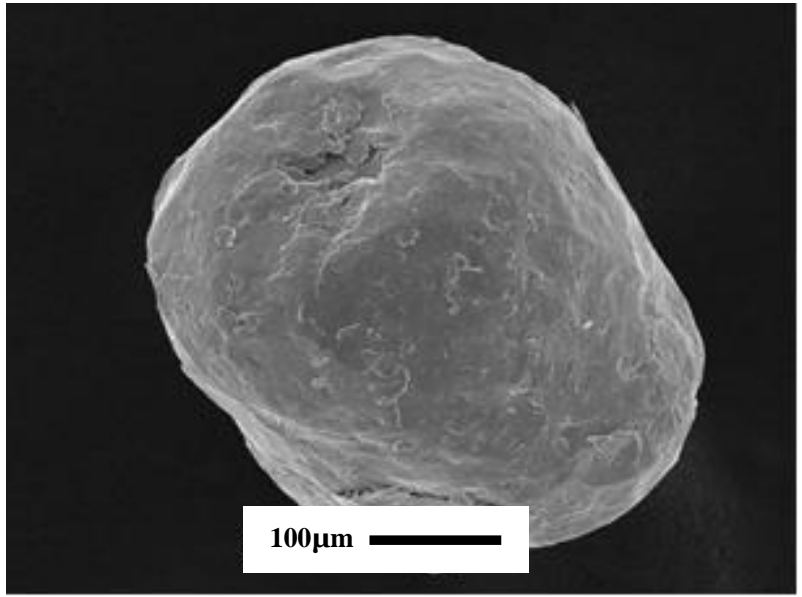

b)

Figure 2. 0.3 mm diameter shots, a) ZSO.3 b) CWO.3

\subsection{Roughness measurements}

The roughness measurements were performed using a Mahr Marsurf M300 roughness tester. Roughness was measured in all specimens after the different treatments. Five roughness profiles were plotted for each specimen and the mean value of the average roughness, $R_{a}$, and the maximum roughness, $R_{\max }$, parameters were obtained. $R_{\max }$ is the maximum of the five $R_{\text {imax }}$ within the assessment length of $4.8 \mathrm{~mm}$, where $\mathrm{R}_{\mathrm{imax}}$ is the maximum peak-to-valley height of the profile in each of the five aforementioned measurements.

\subsection{Determination of the compressive residual stress profile}

Residual stress was determined by means of the X-ray diffraction technique using the $\sin ^{2} \psi$ method onto flat slices with a thickness of $10 \mathrm{~mm}$ obtained cross-sectioning the bar, while the FWHM parameter (diffraction peak width at half maximum height) was simultaneously measured as a parameter related with the induced hardening $[18,19]$. It was demonstrated in a previous work the good correspondence between the residual stress profile measured using flat and fatigue specimens [20]. In order to define the residual stress profiles, thin layers of material were progressively removed step-by-step by electro-polishing using a mixture of $94 \%$ acetic acid and $6 \%$ perchloric acid as electrolyte under a voltage of 40-50V. The slight stress relaxation produced by electro-polishing was also taken into account and corrected in accordance with Sikarskie [21], who has developed a method based on the Moore and Evans procedure [22]. Diffraction data were determined in three different directions $\left(-45,0\right.$ and $\left.+45^{\circ}\right)$ on the sample surface. However, as shot peening stresses are uniform in this plane, average results will be shown. Measurements were made on an X-Stress 3000 G3R device manufactured by Stresstech using the $K \alpha$ chromium wavelength $(\lambda=0.2291 \mathrm{~nm}),(211)$ diffraction planes, which give a diffraction angle around $156^{\circ}$, and an elastic constant, E/(1+v), of $168.9 \mathrm{GPa}$ [23].

The procedure for determining the residual stress began with a surface measurement followed by removal of a layer of around $20 \mu \mathrm{m}$. This process was repeated as many times as necessary until 
reaching a depth at which a residual tensile stress was obtained. The residual stress was always measured on the centre of the specimen, which was previously marked with a permanent marker.

\subsection{Rotating fatigue tests}

Finally, fatigue tests were carried out on a four-point loading R. R. Moore rotating beam fatigue testing system (fully reversed loading, $\mathrm{R}=-1$ ) at room temperature under a nominal frequency of 95 $\mathrm{Hz}(5700 \mathrm{rpm})$. The geometry and dimensions of the fatigue specimens are shown in Fig. 3. The alternating stress at surface was $1100 \mathrm{MPa}(55 \%$ of the tensile strength of the steel). This load was chosen after performing different tests varying this parameter so that it was always above the steel fatigue limit and, in the case of the best treatments, not far from it. The number of specimens tested under each condition varied between 4 and 6. Fatigue results are expressed as an average of all the tested samples, although individual values are also reported. Once the specimens had failed, fractographic analyses were carried out under a SEM microscope to detect the origin of the fatigue crack and the fracture pattern.

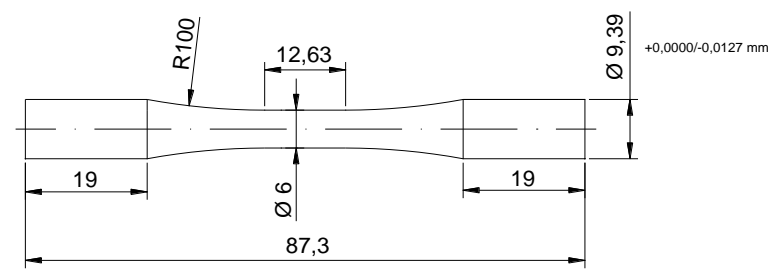

Figure 3. Fatigue sample geometry and dimensions

\section{RESULTS AND DISCUSSION}

\subsection{Roughness}

Table 4 shows the values of the roughness parameters, $R_{a}$ and $R_{\max }$, measured directly on the fatigue samples after the different surface treatments.

Table 4. Roughness parameters after the applied mechanical surface treatments

\begin{tabular}{|l|l|l|}
\hline Treatments & $\mathrm{R}_{\mathrm{a}}(\mu \mathrm{m})$ & $\mathrm{R}_{\max }(\mu \mathrm{m})$ \\
\hline Before SP & $1,3 \pm 0,1$ & $10,5 \pm 1,1$ \\
\hline SP8A-CW(100\%) & $2,1 \pm 0,1$ & $15,9 \pm 2,1$ \\
\hline SP14A-CW(100\%) & $2,5 \pm 1,1$ & $17,4 \pm 2,1$ \\
\hline SP19A-CW(100\%) & $2,8 \pm 1,2$ & $19,5 \pm 2,2$ \\
\hline SP8A-ZS $(100 \%)$ & $1,4 \pm 0,1$ & $11,0 \pm 2,7$ \\
\hline SP8A-ZS(200\%) & $1,8 \pm 0,1$ & $13,3 \pm 2,1$ \\
\hline
\end{tabular}

As could be expected, a significant increase in roughness was detected by increasing the Almen intensity of the treatments when using the cut wire steel shots. However, a significant difference between the roughness generated by the steel and the ceramic beads was observed for the same intensity and coverage (8A, 100\%): shot peening with the ceramic beads (ZS) produced much lower values of average and maximum roughness. These results are undoubtedly explained by the greater 
geometric perfection and homogeneity of the zirconia shots (see Fig. 1 and 2). On the other hand, the increase in the degree of coverage from 100 to $200 \%$ using the same ceramic shots resulted in an increase in the roughness parameters.

However, it was verified in a previous study [24] that roughness is not the best parameter for verifying the existence of surface defects, such as folds and small cracks, typical in shot peening treatments. For this reason the surface topography of the specimens was also explored under the scanning electron microscope, with representative results being shown in Figure 4.

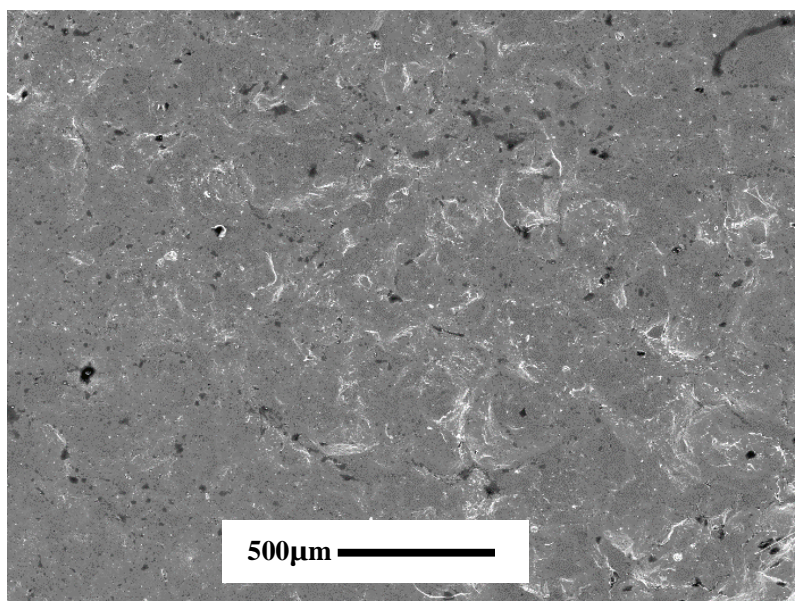

a)

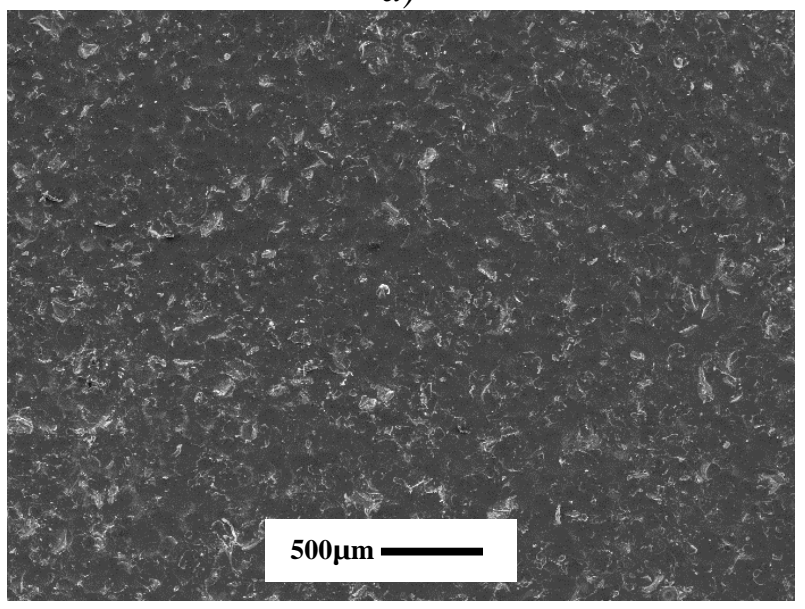

c)

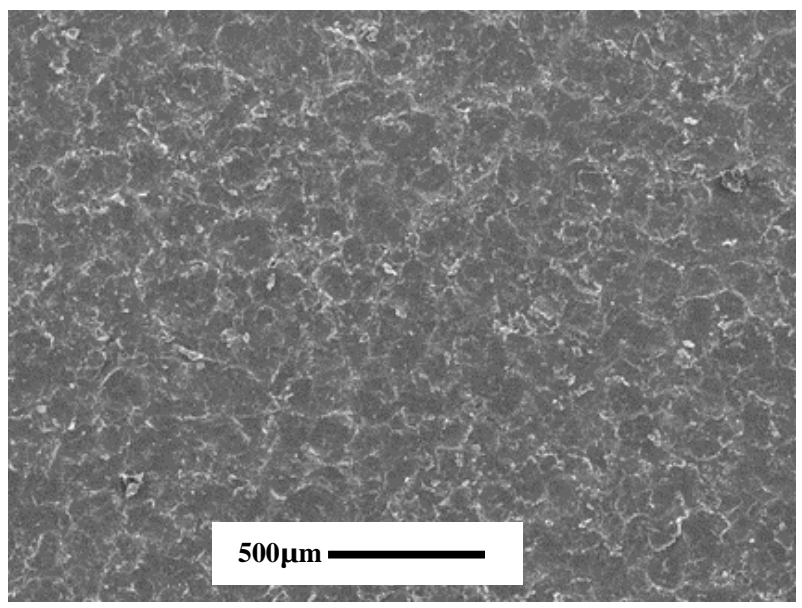

b)

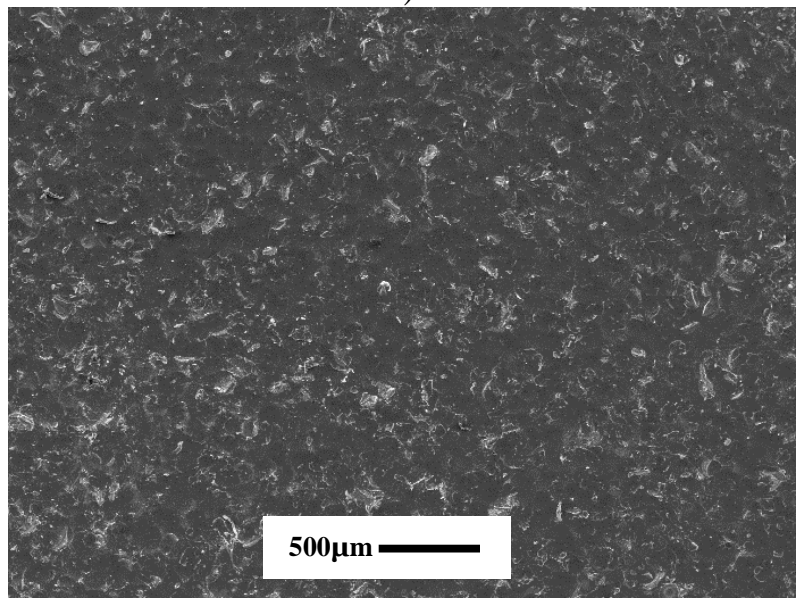

d)

Figure 4. Surface topography after different surface treatments. a) SP19A-CW(100\%) 50x, b) $S P 8 A-C W(100 \%) 50 x, c) S P 8 A-Z S(100 \%) 30 x d) S P 8 A-Z S(200 \%) 30 x$

Under the magnifications shown in Figure 4, differences among treatments are not relevant. However, under a greater magnification (Figure 5), surface defects induced by the mechanical treatments are clearly identified. The sample surface treated with the applied low intensity treatment using ceramic beads (SP8A-ZS) under coverages of $100 \%$ hardly produced any significant defect, while sample surfaces treated with the steel balls always showed small cracks and sharp notches due to shot impacts at high velocity. These results can be justified based on the shape of the shots, previously shown in Figures 1 and 2 (in this respect, the perfect spherical shape of the zirconia shots is once again worth highlighting). On the other hand, the applied treatment using ceramic beads under coverages of $200 \%$ finally gave rise to quite similar defects to those produced when using steel balls. 


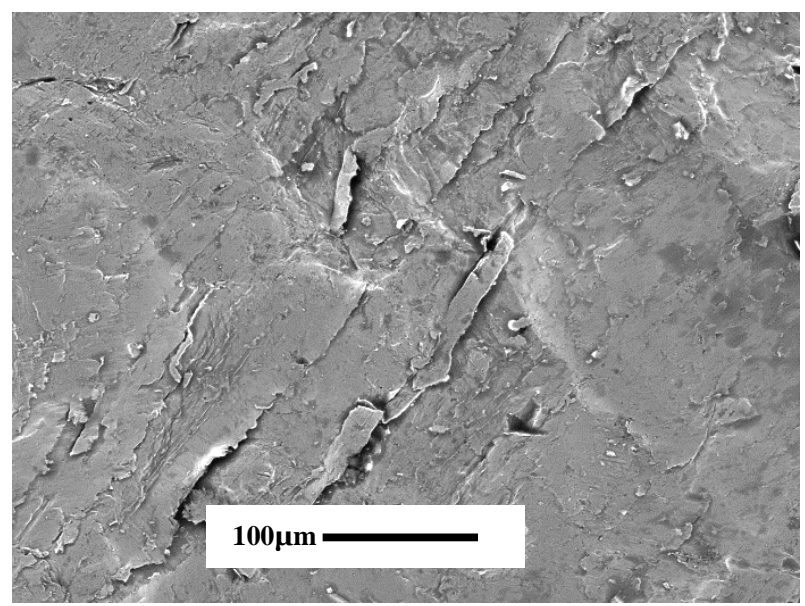

a) $S P 19 A-C W(100 \%)$

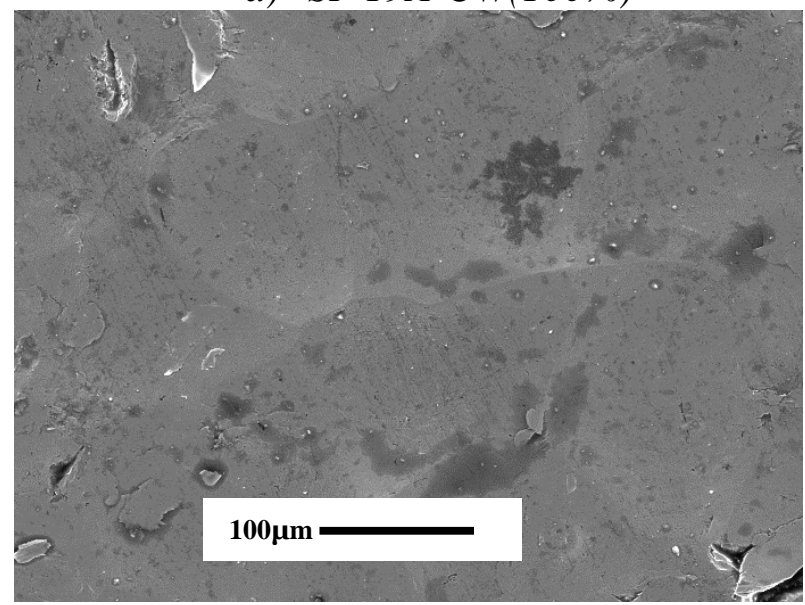

c) $S P 8 A-Z S(100 \%)$

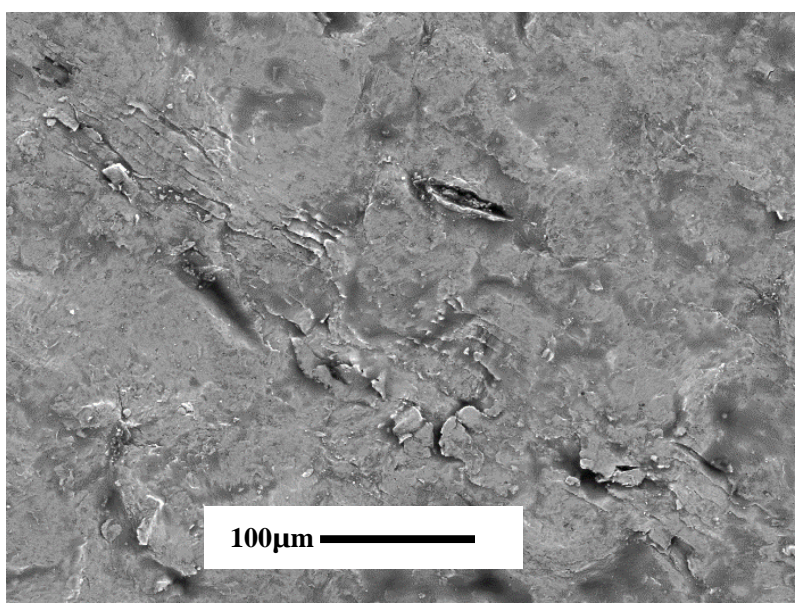

b) $S P 8 A-C W(100 \%)$

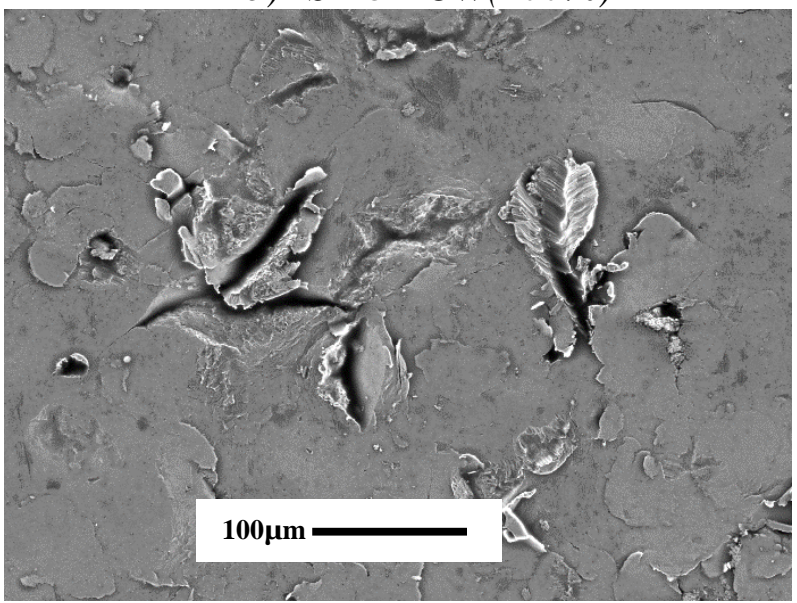

d) $S P 8 A-Z S(200 \%)$

Figure 5. Surface topography after different surface mechanical treatments. 250x.

3.1.Residual stress profiles

Figure 6 shows the residual stress profiles generated after applying the studied surface treatments. 


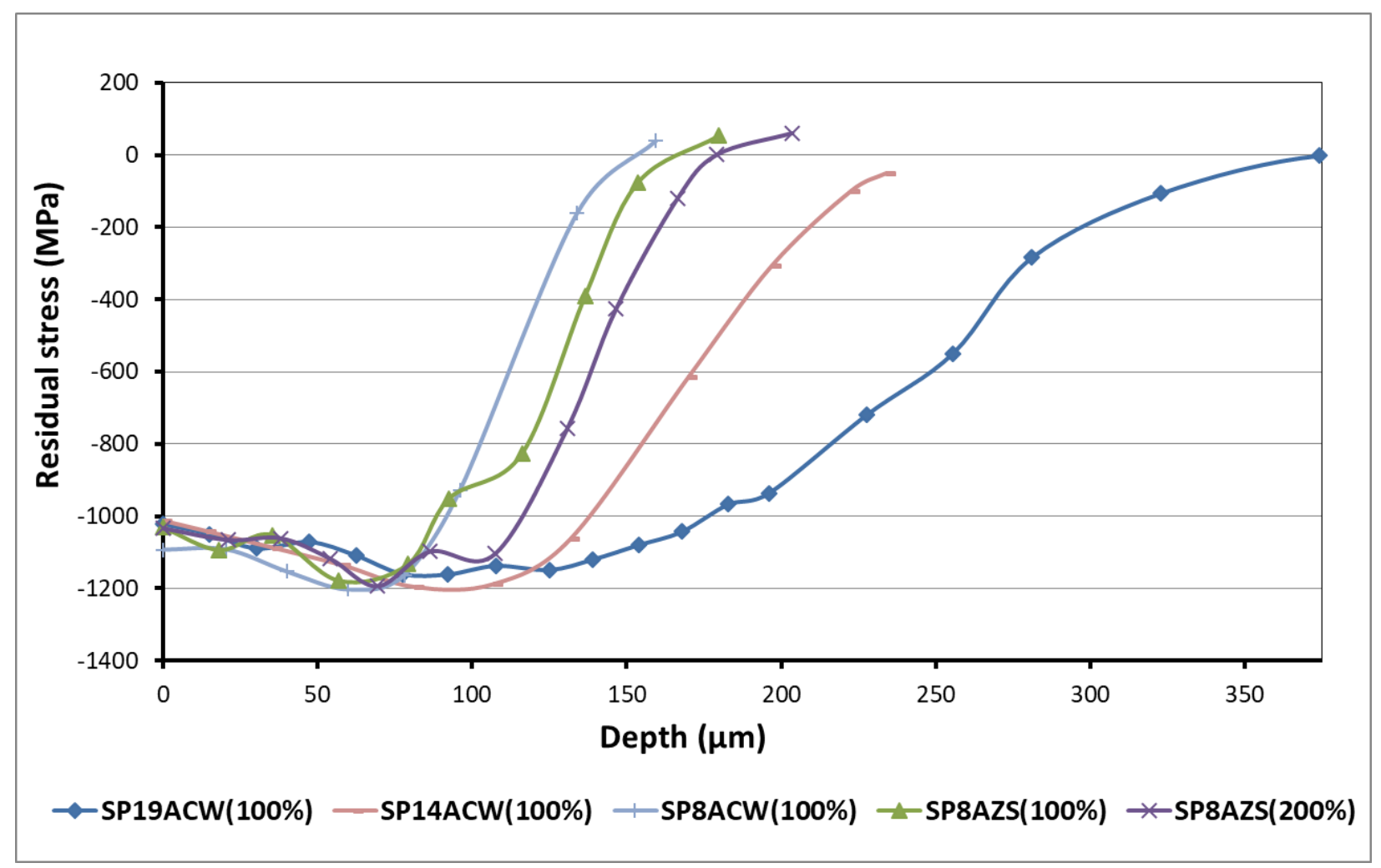

Figure 6. Residual stress profiles corresponding to the different surface treatments

Profiles shapes corresponding to the same intensity (8A) are quite similar, revealing a surface compressive residual stress with a magnitude of between 1000 and $1050 \mathrm{MPa}$ and a maximum compressive residual stress of around $1200 \mathrm{MPa}$ located at a depth of $60-70 \mu \mathrm{m}$ followed by a progressive increase in stress until reaching small positive values, thus defining the depth affected by the residual compressive stress field. Only a small increase in the depth submitted to compressive residual stresses was observed when zirconia beads were used instead of steel shots (8A) and also when coverage was increased to $200 \%$ using the ceramic beads. The small profile change due to the use of the ceramic beads is justified by their greater hardness (Table 3) [3].

The residual stress profiles measured in the case of the highest intensity treatments (obtained using steel balls) were nearly similar at low depths $(<70-80 \mu \mathrm{m})$, the greatest difference being the depth submitted to compressive residual stresses (denominated $\mathrm{Z}_{0}$ ), which increases as the intensity of the treatment increases. The $\mathrm{Z}_{0}$ values measured in all the mechanical treatments are shown in Table 5.

Table 5. Depth under compressive residual stresses

\begin{tabular}{|l|l|}
\hline Treatment & $\mathrm{Z}_{0}(\mu \mathrm{m})$ \\
\hline SP19A-CW $(100 \%)$ & 375 \\
\hline SP14A-CW $(100 \%)$ & 250 \\
\hline SP8A-CW $(100 \%)$ & 150 \\
\hline SP8A-ZS $(100 \%)$ & 165 \\
\hline SP8A-ZS $(200 \%)$ & 175 \\
\hline
\end{tabular}

The profile of the full width at half maximum parameter (FWHM) can be seen in Figure 7. The evolution of this parameter in this high strength steel is worth highlighting. There is a clear increase in this parameter (hardening) near the surface of the samples, although this reaches a minimum at a 
depth of between 80 and $100 \mu \mathrm{m}$ from the surface and then increases until reaching the level corresponding to the base steel $\left(5.8^{\circ}\right)$. The observed decrease in the FWHM parameter in this steel at the aforementioned depth, also observed in other high strength steels [13], is probably the result of dislocation re-arrangement. Due to quenching followed by a low temperature tempering, the base steel has a high distorted structure with a high hardness and peening-induced plastic deformation resulted in a lower-energy dislocation arrangement. This consequently gave rise to a reduction in the FWHM parameter in the sub-surface regions, although an increase in FWHM was observed in the first 80-100 $\mu \mathrm{m}$.

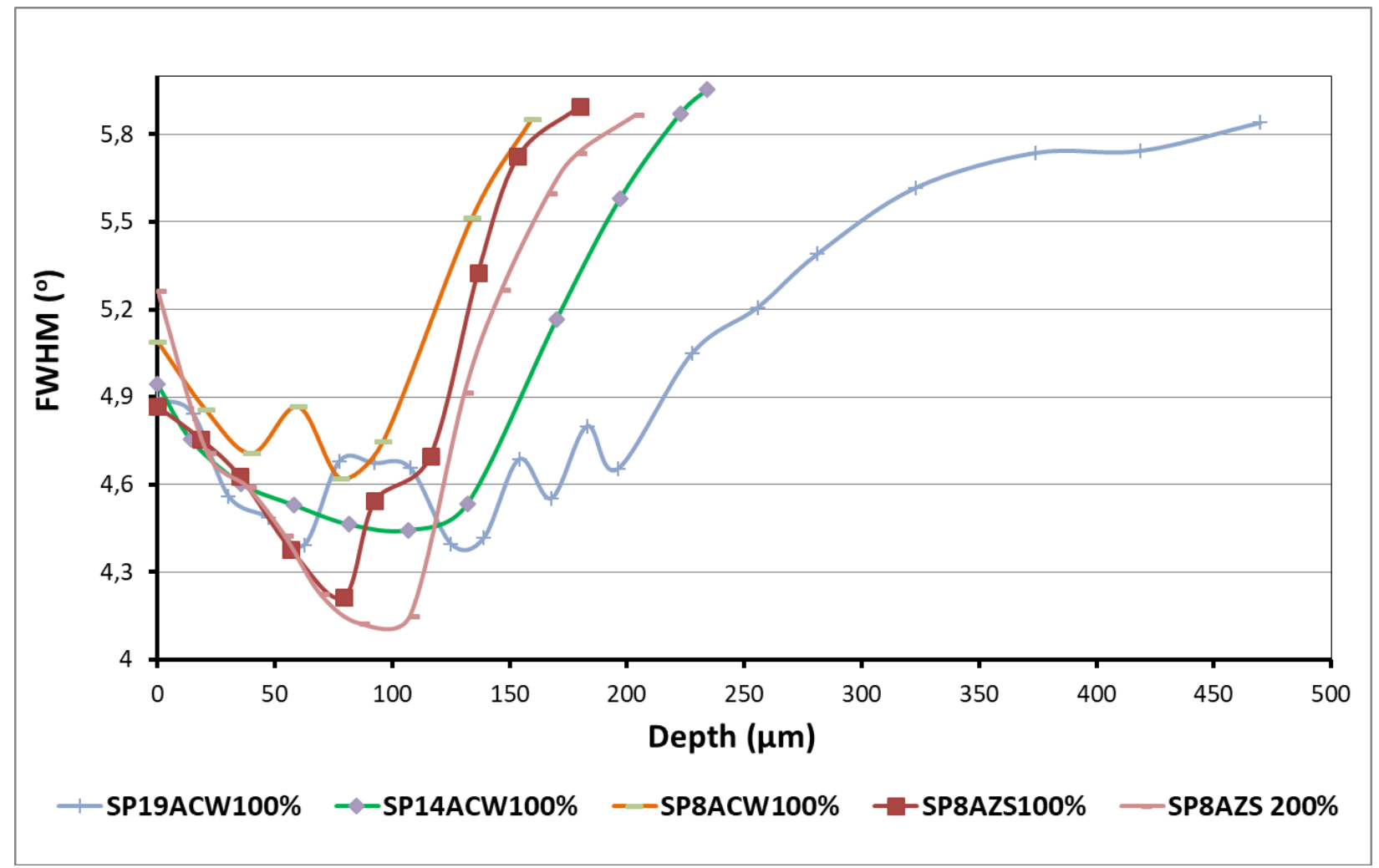

Figure 7. FWHM profiles measured in the different surface treatments

Surface hardening produced by shot peening treatments is best represented as the difference between the superficial FWHM and the minimum FWHM (stabilized microstructure due to shot peening), values which are shown in Table 6. This index is a clear indication of the effect produced in the sample surface by the plastic deformation produced by the repeated shot impacts. Ceramic beads induce a higher hardening effect due their much higher hardness compared with steel shots (see Table 3 ), this effect also being much more notable in the case of the $200 \%$ coverage treatment. It should likewise be recalled here that the excessive surface plasticity and hardening induced in the latter case also produced significant surface defects (Figure $5 \mathrm{~d}$ ).

Table 6. Surface hardening $\left(\mathrm{FWHM}_{\text {sup }}-\mathrm{FWHM}_{\min }\right)$

\begin{tabular}{|l|c|c|c|}
\hline Treatment & FWHM $_{\text {sup }}$ & FWHM $_{\min }$ & Surface hardening index $\left(^{\circ}\right)$ \\
\hline SP19A-CW (100\%) & 4,89 & 4,39 & 0,5 \\
\hline SP14A-CW (100\%) & 4,94 & 4,44 & 0,5 \\
\hline SP8A-CW (100\%) & 5,09 & 4,62 & 0,47 \\
\hline SP8A-ZS (100\%) & 4,86 & 4,21 & 0,65 \\
\hline SP8A-ZS (200\%) & 5,26 & 4,12 & 1,14 \\
\hline
\end{tabular}




\subsection{Fatigue lives}

Figure 8 shows the individual and the average fatigue life results obtained after the application of the studied mechanical treatments. The fatigue results obtained for the untreated specimens (NSP) are also shown for the sake of comparison. It should first be noted that all the applied surface treatments improved the fatigue behaviour of the untreated specimens at least by a factor of 2.5.

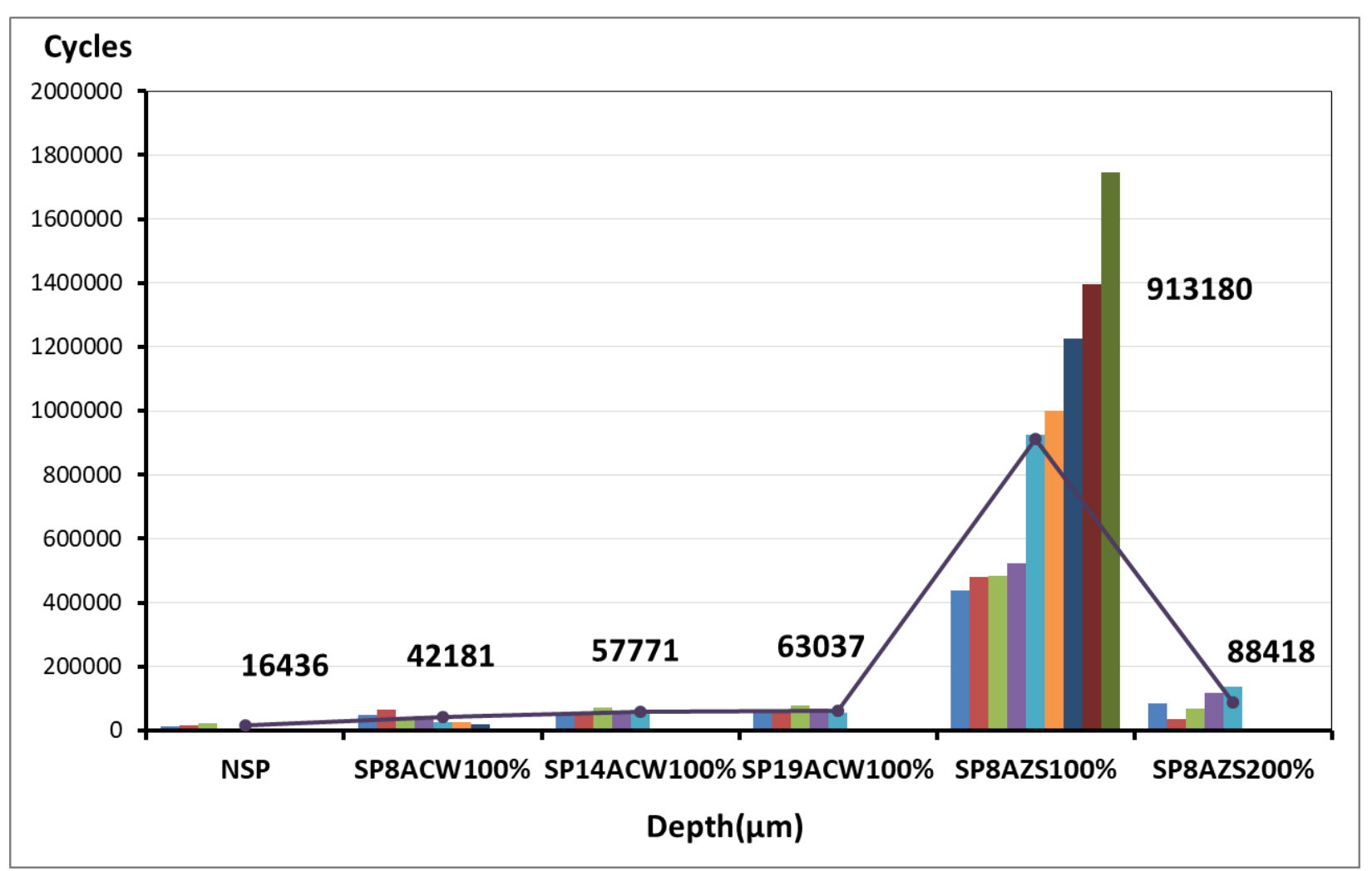

Figure 8. Average fatigue lives and individual results (bars) under rotating bending. Maximum applied stress of $1100 \mathrm{MPa}$

Shot peening with zirconia beads under an intensity of $8 \mathrm{~A}$ and $100 \%$ coverage produced a much longer fatigue life than that obtained with the rest of the evaluated surface treatments. An average fatigue life under this high alternating stress greater than 900,000 cycles was measured, the lowest fatigue lives on individual specimens always being greater than 400,000 cycles, a fatigue life which was never attained in any individual test performed with the other treatments. The main distinctive characteristic of this treatment is the much lower surface damage induced by the impacts with the ceramic shots under $100 \%$ coverage (see Figure 5), which in turn was already justified by the perfect spherical shape of these projectiles.

Moreover, Figure 8 also shows the major deterioration in fatigue life produced by prolonging the surface treatment when using zirconia beads. After the $200 \%$ coverage using zirconia beads, fatigue life decreased more than 10-fold due to the surface damage finally induced after such a prolonged mechanical treatment (see Figure 5).

On the other hand, while greatly increasing the depth affected by the residual compression stresses (Table 5), the use of steel shots under higher intensities also induces much greater surface damage, which limits the aforementioned beneficial effect. Both effects, the depth submitted to compressive stresses and the magnitude of surface defects nearly offset one another. Hence, fatigue lives were 
hardly different when the intensity was varied between 8A to 19A using steel shots (average fatigue lives of between 40,000 and 60,000 cycles).

It should be recalled here that the fatigue tests were carried out under rotating bending loads, where the alternating stress $(1100 \mathrm{MPa})$ reached its maximum value on the surface of the specimen, descending linearly until reaching zero on the specimen's central axis, located at a depth of $3 \mathrm{~mm}$ (specimens with a diameter of $6 \mathrm{~mm}$ ). Under these conditions, fatigue cracks are expected to initiate on the surface of the specimen. Surface fatigue initiation took place in all the treatments using cut wire steel shots and also in those using ceramic beads under $200 \%$ coverage due to the previously mentioned surface defects. Two representative examples of surface fatigue crack initiation can be seen in Fig. 9 a) and b). However, all the specimens treated with zirconia shots and 100\% coverage failed due to fatigue cracks internally initiated at hard inclusions located at depths greater than 165 $\mu \mathrm{m}$ (value of $\mathrm{Z}_{0}$ in Table 5). That is, fatigue crack initiation always took place in these tests in the region not affected by the residual compressive stresses induced by the mechanical treatment.

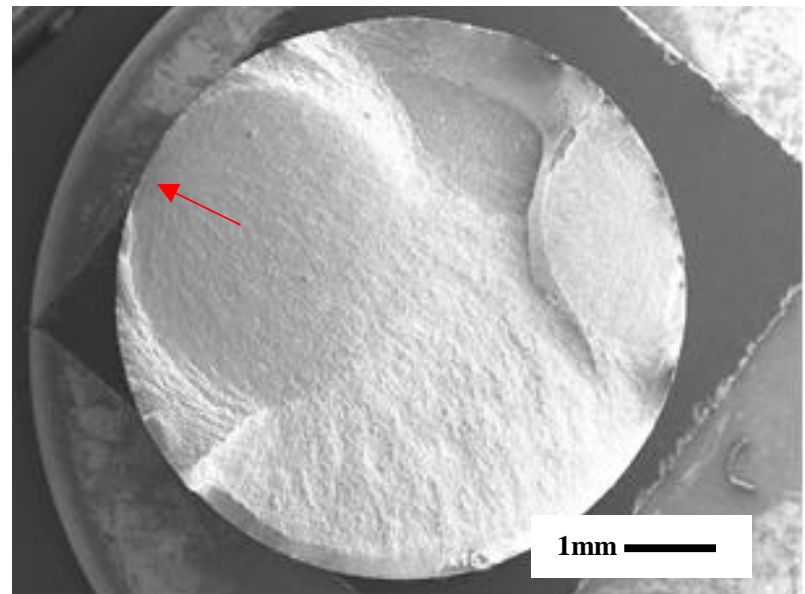

a)

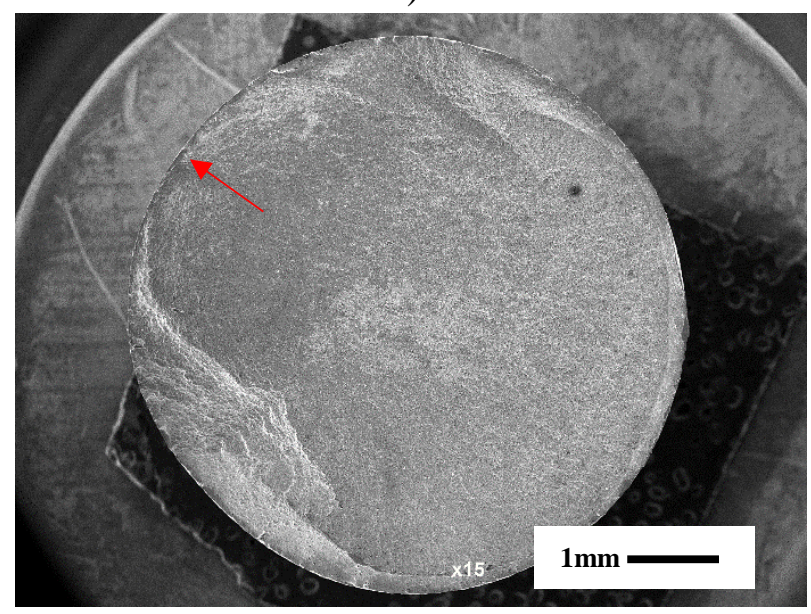

c)

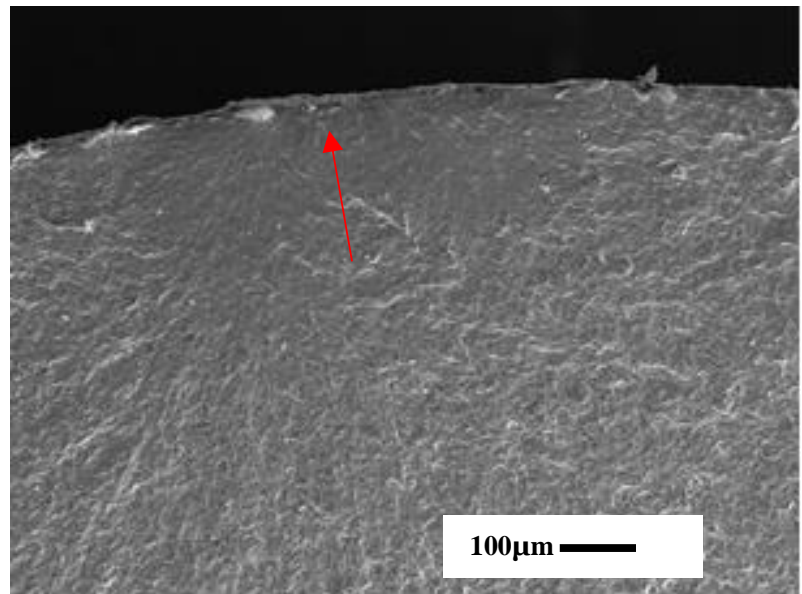

b)

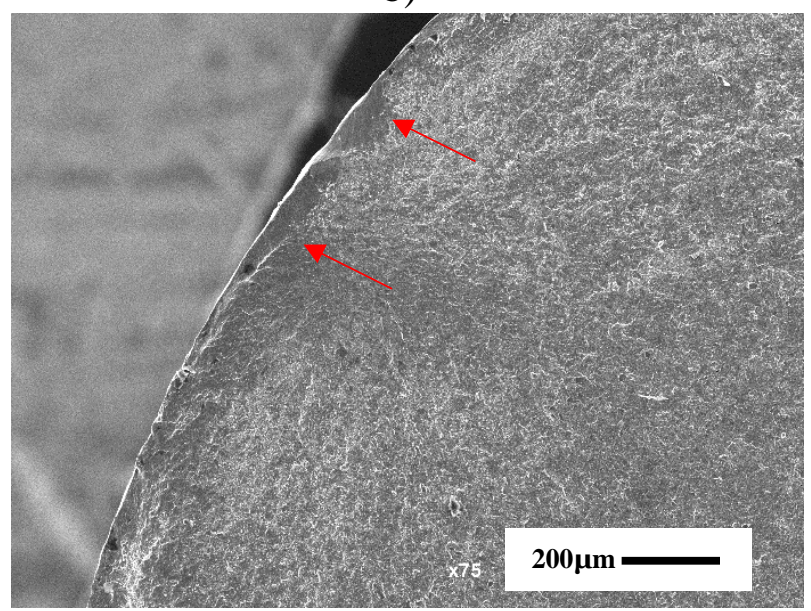

d)

Figure 9. Fatigue failure of fatigue samples submitted to different mechanical treatments: a) SP8A-CW(100\%) 15x, b) SP8A-CW(100\%) 120x, c) SP8A-ZS(200\%) 15x y d) SP8A-ZS(200\%) 75x. Arrow shows the initiation site.

Internal fatigue crack initiation of the specimens submitted to $8 \mathrm{~A}$ intensity using zirconia beads and $100 \%$ coverage are presented in Figure 10. Magnified images of the fatigue crack initiation zones in all the aforementioned specimens can also be seen in the same figure. Internal crack initiation usually 
took place around hard non-metallic inclusions, which were analysed under the scanning electron microscope, being in all cases mixed oxides of aluminium, magnesium and/or calcium. The measured depth where fatigue crack have initiated varied between $183 \mu \mathrm{m}$ and $300 \mu \mathrm{m}$, while depth under compressive residual stresses, $\mathrm{Z}_{0}$, was $165 \mu \mathrm{m}$ (Table 5) in these shot peened specimens.
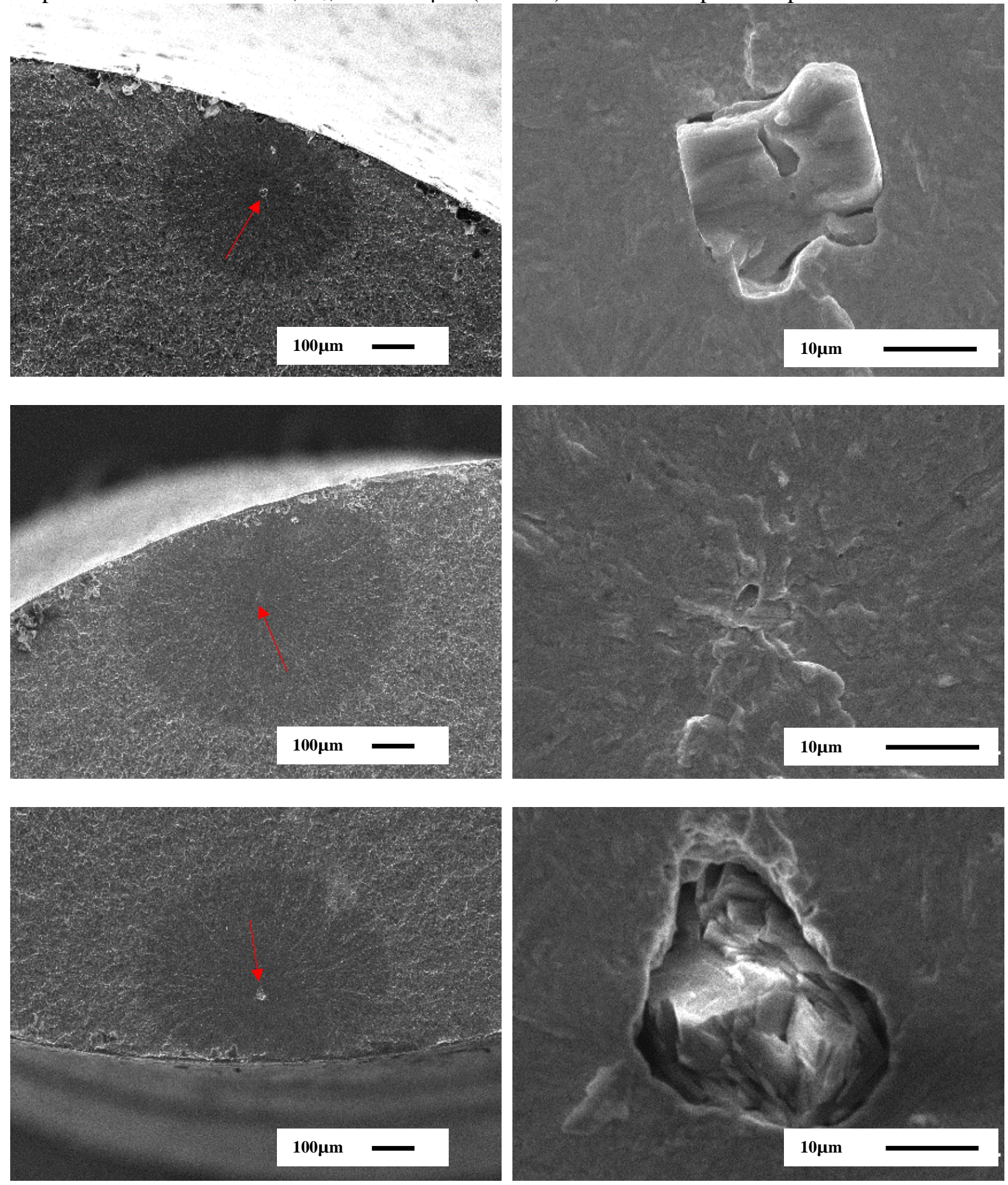

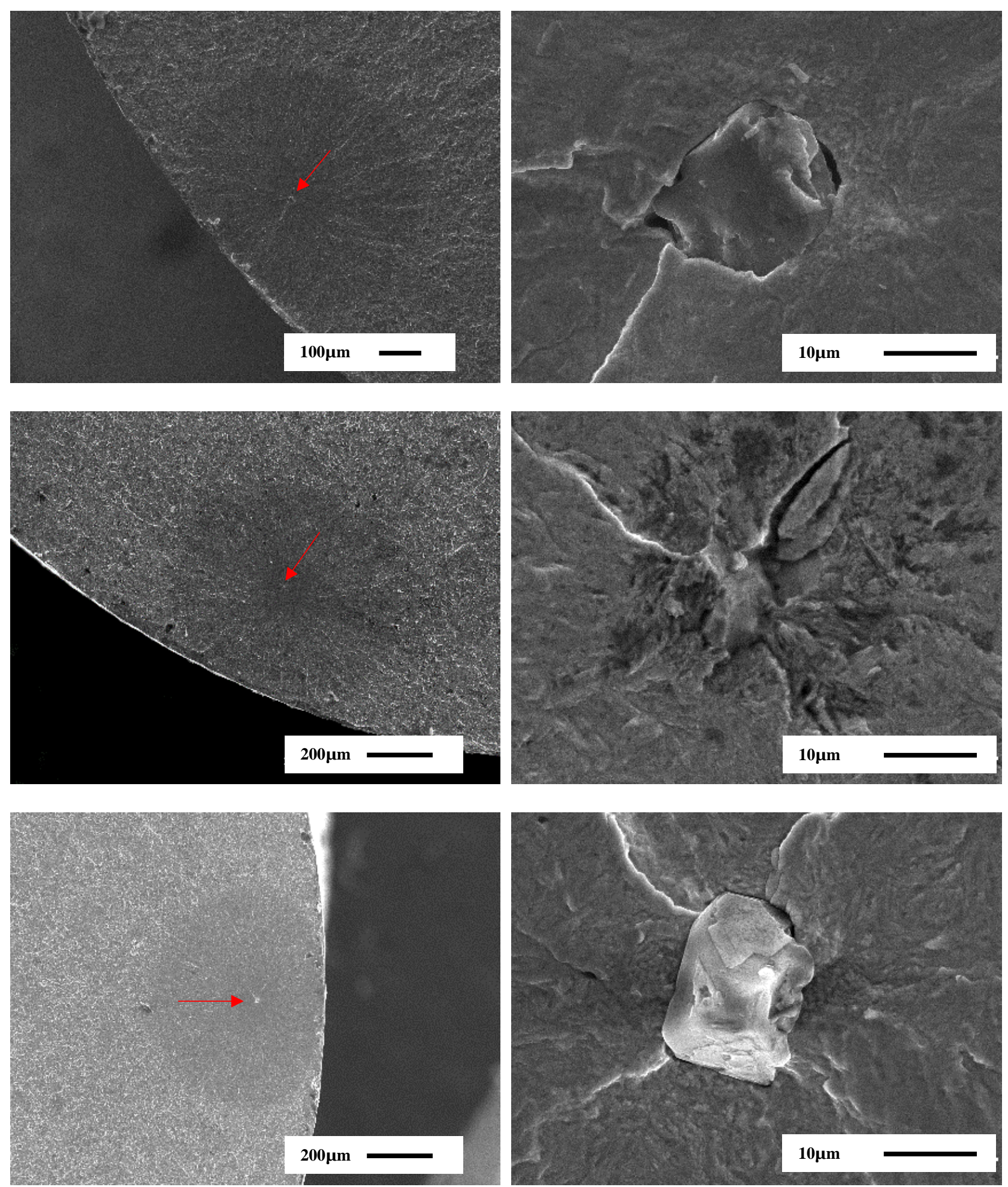

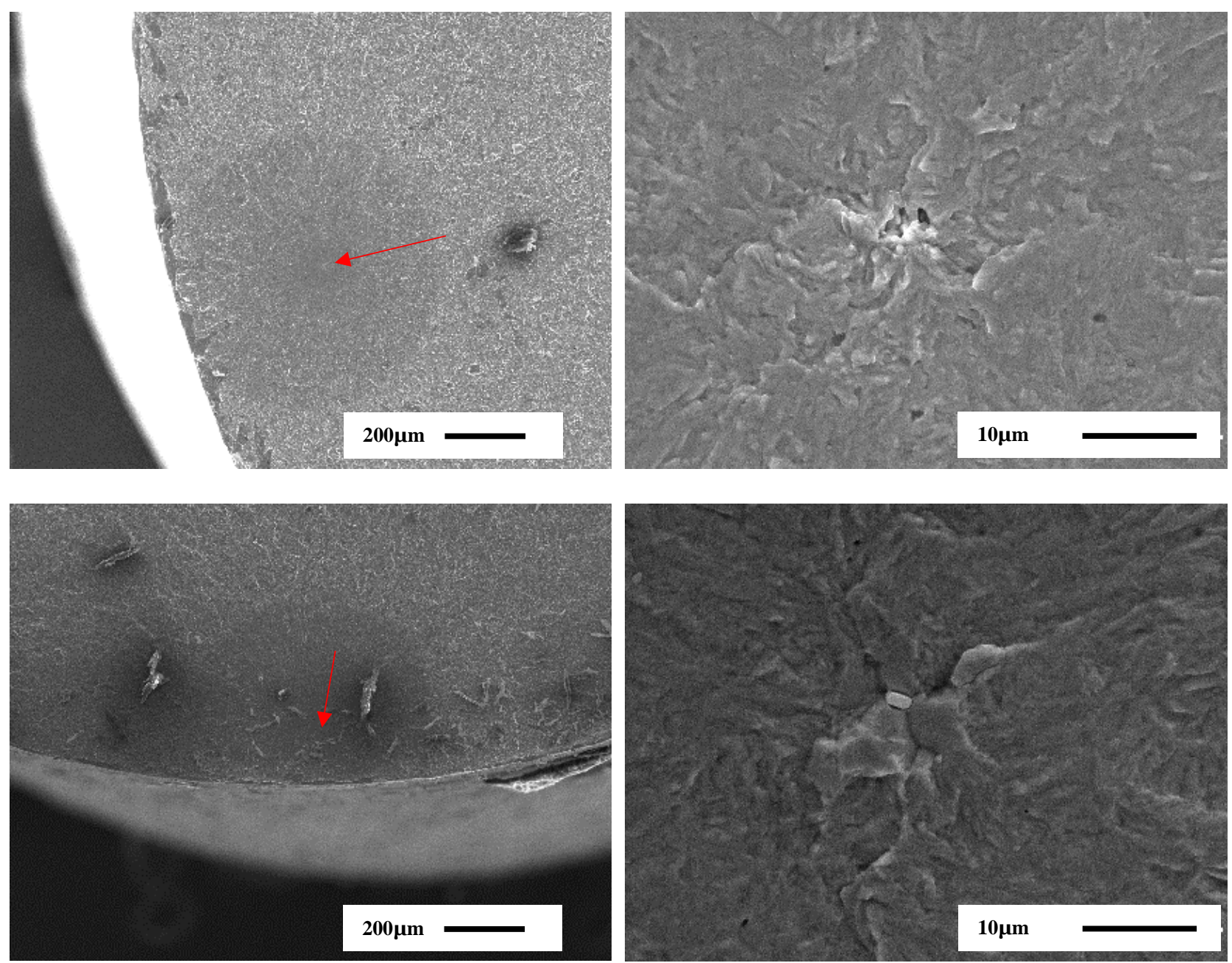

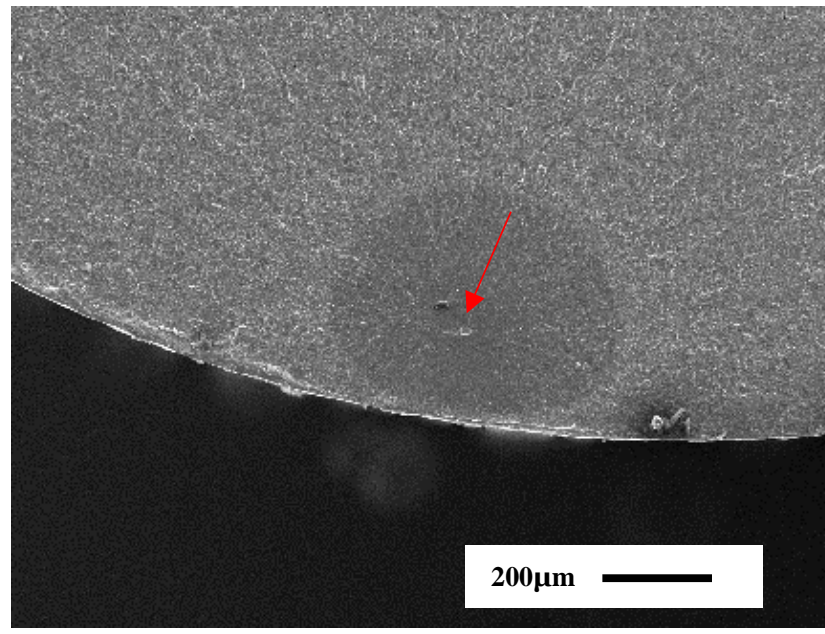

a)

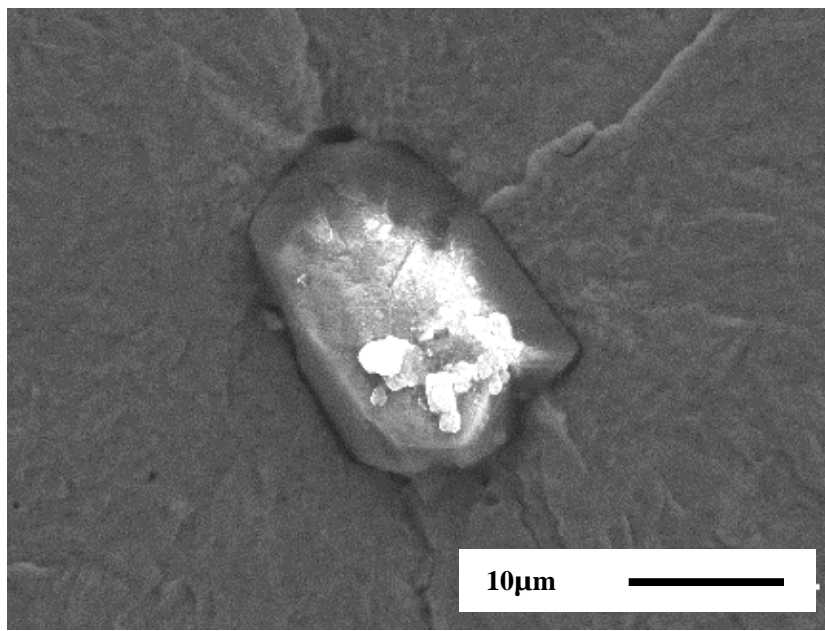

b)

Figure 10. Fatigue crack initiation region after SP8A-ZS(100\%) treatment. Alumina inclusion. a) $75 x-100 x$ y b) 2500x. Arrow shows the initiation site.

A fatigue crack initiates internally when the stress concentration factor due to surface defects generated by shot peening is minimized. This is because the compressive residual stress belt induced in this case is able to avoid crack growth from the defects existing in the surface region, consequently triggering an internal fatigue crack propagation process. Residual compressive stresses at the 
specimen surface promote crack closure, reducing the effective stress intensity range, $\Delta \mathrm{K}_{\mathrm{eff}}$, which is the factor directly related with the fatigue crack growth rate. When $\Delta \mathrm{K}_{\mathrm{eff}}$ is lower than the stress intensity range threshold of the steel product, $\Delta \mathrm{K}_{\mathrm{th}}$, crack growth does not take place and fatigue crack initiation is avoided. Nevertheless, the aforementioned effect disappears when the residual compressive belt is surpassed $\left(d>Z_{0}, \sigma_{R} \approx 0\right)$. In this case the presence of a hard inclusion gives rise to a local microstructural stress concentrator, were the applied $\Delta K$ surpasses the steel $\Delta K_{\text {th }}$ threshold. Fig. 11 shows the residual stress profile $\left(\sigma_{\mathrm{r}}\right)$ and the magnitude of the applied alternating stress $\left(\sigma_{\mathrm{a}}\right.$, it varies lineally along the specimen radius), along with crack growth criteria, acting at a surface defect and at an internal inclusion.

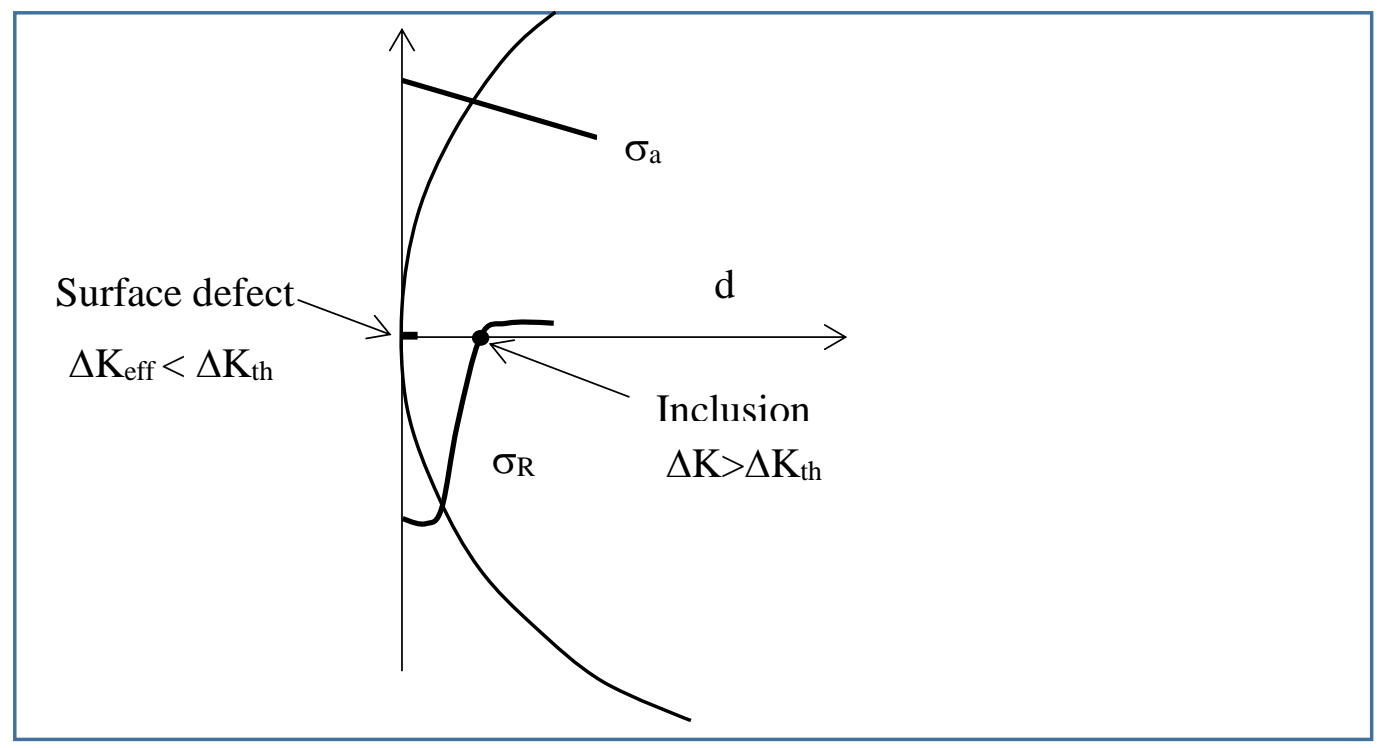

Figure 11. Residual stress and alternating stress versus the specimen depth. Conditions for internal fatigue crack initiation

It is also important to consider the residual stress relaxation due to local plasticization in the compressive part of the fatigue cycle. We have measured the surface residual stress relaxation on some of the aforementioned fatigue tests and values between $9 \%$ and $28 \%$ were measured, with an average surface relaxation value of $18 \%$ [25]. This effect being quite low, may be disregarded in this discussion.

Following this analysis, it may hence be stated that the so-called internal fatigue damage mechanism is non-dependent on surface characteristics, depending only on the microstructure of the steel, specifically on the existence of microstructural stress concentrators such as alumina or other types of hard non-metallic inclusions.

It is also worth highlighting that the dispersion of the SP8A-ZS(100\%) fatigue results observed in Figure 6 is not due to the applied surface treatment, but to the statistical distribution of the hard and rigid inclusions present in this steel. Under this consideration, the best way to improve the fatigue strength of the steel, once the surface has been protected by means of an appropriate mechanical treatment, would be to use special processing techniques to obtain a cleaner product with lower inclusion densities and inclusions of smaller sizes. 


\section{CONCLUSIONS}

Hardly any significant defect was produced on surfaces treated with low intensity treatment using zirconia beads (SP8A-ZS) under 100\% coverages, while sample surfaces treated with steel balls under the same intensity always showed small cracks and sharp notches caused by high velocity shot impacts. These results were justified by the perfect spherical shape of the zirconia shots.

The residual stress profiles produced after the application of the different surface treatments using different types of shots, intensities and coverages were very similar for depths lower than 70-80 $\mu \mathrm{m}$, the main difference being the depth affected by the presence of compressive residual stresses, which slightly increases when using zirconia beads and with increasing coverage, the increase of this parameter being much more significant when the intensity of the treatment increases.

Shot peening with zirconia beads under an intensity of $8 \mathrm{~A}$ and $100 \%$ coverage gave rise to a much longer fatigue life than that obtained with the rest of the evaluated surface treatments. The main distinctive characteristic of this treatment is the much lower surface damage induced by the impacts with the ceramic shots under $100 \%$ coverage, which was in turn already justified by the perfect spherical shape of these projectiles. Moreover, a major deterioration in the fatigue life was produced by prolonging the surface treatment with the zirconia beads. After a 200\% coverage treatment, fatigue life decreased more than 10-fold due to the surface damage finally induced as a consequence of excessive plastic surface deformation following such a prolonged mechanical treatment.

Furthermore, the treatment with zirconia shots under an intensity of $8 \mathrm{~A}$ and $100 \%$ coverage always gave rise to internal initiation of the fatigue crack at a depth where the residual compression stresses induced in the treatment disappeared and due to the stress concentration associated with the presence of hard and rigid non-metallic inclusions, even though the applied rotational bending fatigue tests always produced the maximum alternating stress on the surface of the test specimen.

\section{REFERENCES}

[1] MIC, Shot Peening Applications, 8th ed., Metal Improvement Company, USA, 2001.

[2] MFN, Shot peening:A dynamic application and its future, Metal Finishing News, Switzerland, 2009.

[3] J. Kritzler and W. Wübbenhorst, Inducing compressive stresses through controlled shot peening, in Hand book of residual stresses and deformation of steel, ASM International, 2003, 345-358.

[4] P. Sanjurjo, C. Rodríguez, I. Peñuelas, T.E. García, F.J. Belzunce, Influence of the target material constitutive model on the numerical simulation of a shot peening process, Surface \& Coatings Technology, 258, 2014, 822-831. 
[5] M. Taro, T. Chaise and D. Nelias, A methodology to predict roughness of shot peened surfaces, Journal of Materials Processing Technology, 217, 2015, 65-76.

[6] A.Gariepy, H.Y. Miao and M. Levesque, Simulation of shot peening process with variable shot diameters and impacting velocities, Advances in Engineering Software, 114, 2017, 121-133

[7] F. Tu, D. Delbergue, H. Miao, T. Klotz, M. Brochu, P. Bocher, M. Levesque, A sequential DEMFEM coupling method for shot peening simulation, Surface \& Coatings Technology, 319, 2017, 200212.

[8] S. Tekeli, Enhancement of fatigue strength of SAE 9245 steel by shot peening, Matter, Lett, 57, 2002, 604-608.

[9] M.L. Aggarwald, R.A. Khan and V.P. Aggarwald, Influence of shot peening intensity on fatigue desing reliability of $65 \mathrm{Si} 7$ spring steel, Indian J. Eng. Mater. Sci., 12, 2005, 515-520.

[10] M.A.S. Torres and H.J.C. Voorwald, An evaluation of shot peening, residual stress and stress relaxation on the fatigue life of AISI 4340 steel, Int. J. Fatigue, 24, 2002, 877-886

[11] A.T. Vielma, V. Llaneza, F.J. Belzunce, Effect of coverage and double peening treatments on the fatigue life of a quenched and tempered structural steel, Surface \& Coatings Technology, 249, 2014,75-83.

[12] V. Llaneza and F.J. Belzunce, Optimal shot peening treatments to maximize the fatigue life of quenched and tempered steels, Journal of Materials Engineering and Performance, 24-7, 2015, 28062815.

[13] V. Llaneza and F.J. Belzunce, Study of the effects produced by shot peening on the surface of quenched and tempered steels: roughness, residual stresses and work hardening, Applied Surface Science, 356, 2015, 475-485.

[14] F. Peng, K. Zhan, J. Chuanhai, Micro-structure and surface layer properties of 18CrNiMo7-6 steel after multistep shot peening, Materials and Design, 51, 2013, 309-314.

[15] F. Abadie, Enhancement of Shot Peening performance on high strength steel parts. Metal Finishing News. Vol 11, July 2010, 16-18.

[16] SAE, Test strip, holder and gage for shot peenning, J442, SAE standard, SAE International, Warrendale, 2008

[17] SAE, Procedures for using standard shot peening test strip, J443, SAE standard, SAE International, Warrendale, 2003

[18] I.C. Noyan, I.C., J.B. Cohen, Residual stress: Measurement by diffraction and interpretation, MRE, Springer-Verlag, New York, 1987.

[19] P.S. Prevey, X-ray diffraction residual stress techniques, in Volume 10, Materials Characterization, Metals Handbook, ASM International, 1986

[20] A. T. Vielma, Ph.D. thesis, university of Oviedo, October 2013. 
[21] D.L. Sikarskie, On a series form of correction to stresses measured using X-ray diffraction, AIME Transactions, 1967, p. 239

[22] M.G. Moore, M.G., W.P. Evans, Mathematical correction for stress in removed layers in X-ray diffraction residual stress analysis, SAE Transactions, 1958, p. 66

[23] NPL, Determination of residual stresses by X-ray diffraction, Document No. 52, National Physical Laboratory, UK, 2005.

[24] E. Segurado, F.J. Belzunce, The use of double surface treatments to increase the fatigue life of a quenched and tempered high-strength steel, Surface Modification Technologies XXIX, Edit. T.S. Sudarshan and N.A.J. Sommers, 2016, 38-46

[25] V. Llaneza, Ph.D. thesis, university of Oviedo, October 2014. 